\title{
El yacimiento de Agra dos Castros (Lugo) a través de su cerámica común
}

\section{The site of Agra dos Castros (Lugo) and its common pottery}

\author{
SARA BARBAZÁn DOMÍngUEZ \\ EDUARDO RAMIL REgO \\ Hugo Lozano Hermida \\ Museo de Prehistoria e Arqueoloxía de Vilalba \\ Rúa Dr. Domingo Goas, 2, E-27800 Vilalba (Lugo) \\ sarabzn@gmail.com \\ director@museovilalba.org \\ hugo.lozano.hermida@gmail.com
}

Presentem els resultats de l'estudi de la ceràmica comuna procedent del castre d'Agra dos Castros (Lugo), situat als afores de l'actual ciutat de Lugo. Sembla que aquest castre va iniciar les seves ocupacions en un moment anterior al canvi d'era, i es va continuar transformant a l'abric del desenvolupament de Lucus Augusti. En aquest treball intentarem caracteritzar tipològicament les seves produccions ceràmiques i determinar l'evolució cronològica de la seva ocupació, matisant tant com sigui possible les fases establertes prèviament. El seu estudi ens ajudarà a definir les produccions ceràmiques d'aquesta època i a precisar l'àmbit d'influència de la civitas.

\section{PARAULES CLAU}

ÈPOCA ROMANA, NORD-OEST DE LA PENÍNSULA IBÈRICA, CASTRES, LUCUS AUGUSTI, CERÀMICA

This paper presents the results of the study of common pottery from the hillfort of Agra dos Castros (Lugo), located on the outskirts of the current city of Lugo. This hillfort seems to begin its occupation at some time prior to the change of era, continuing its development under the protection of Lucus Augusti. Here we will try to characterize the (local) pottery production and wares typologically and determine the chronological evolution of the site's occupation, qualifying, as far as possible, the previously established phases. The study of this site assemblage will help us to define the wares produced in this period as well as determine the sphere of influence of the civitas.

\section{KEYWORDS}

ROMAN PERIOD, NORTH-WESTERN IBERIAN PENINSULA, HILLFORTS, LUCUS AUGUSTI, POTTERY 
Presentamos los resultados del estudio de la cerámica común procedente del castro de Agra dos Castros (Lugo), situado en las afueras de la actual ciudad de Lugo. Este castro parece iniciar sus ocupaciones en un momento anterior al cambio de era, continuando sus transformaciones al abrigo del desarrollo de Lucus Augusti. En este trabajo trataremos de caracterizar tipológicamente sus producciones cerámicas y determinar la evolución cronológica de su ocupación, matizando en la medida de lo posible las fases establecidas previamente. Su estudio nos ayudará a definir las producciones cerámicas de esta época y a precisar el ámbito de influencia de la civitas.

\section{PALABRAS CLAVE}

ÉPOCA ROMANA, NOROESTE DE LA PENÍNSULA IBÉRICA, CASTROS, LUCUS AUGUSTI, CERÁMICA

\section{Introducción}

Este trabajo se enmarca en una investigación (Barbazán, 2019) en la que se planteó el análisis de la cerámica común como un factor a tener en cuenta para entender el intercambio cultural dentro del proceso romanizador que se dio en el noroeste de la península ibérica durante época romana y así comprender los procesos de cambio e hibridación cultural (Hales y Hodos, 2010) vividos aquí con la introducción de este territorio en el mundo romano. Como marco temporal, nos centramos en yacimientos que presentan ocupaciones situadas entre el siglo i a. C. y el siglo v d. C., y como límite geográfico se delimitó la provincia de Lugo debido a que adolece de una escasez de estudios arqueológicos de este tipo.

El objetivo era comprobar cómo se comportaba aquí la actividad alfarera y qué similitudes o diferencias existían respecto al área bracarense y el área asturicense, zonas con producciones alfareras de época romana estudiadas y caracterizadas (Alarçao, 1975; Sánchez y Fernández, 1985; Esparza, 1987; Díaz y Garín, 1999; Morillo et al., 2005; Villa et al., 2008; Delgado et al., 2009; Hevia y Montes, 2009; Morais y Sousa, 2015). En el marco de esta investigación se estudiaron las colecciones de cerámica común del castro de Agra dos Castros (Marcelle, Lugo), un yacimiento situado en las proximidades de la antigua ciudad romana de Lucus Augusti, capital del conventus Lucensis, que tendrá su desarrollo a partir del siglo I d. C. en adelante.

Habitualmente en Galicia estas investigaciones se han llevado a cabo de manera algo desigual. Sobre las producciones cerámicas de la ciudad de Lugo tenemos diversos estudios (Alcorta, 2005a, 2005b, 2005c, 2006; Alcorta et al., 2011, 2012, 2014, 2015; Bartolomé, 2015; Bartolomé y López, 2015). El estudio de referencia para la cerámica común de la zona de Lugo (Alcorta, 2001), aunque es de uso indispensable, en ocasiones presenta una clasificación ambigua debido al uso de criterios como la decoración (tipos L2, L4, L6, L8, L13, L16, O6, O10, O12 hasta O15, O17 hasta O20, O22, O23, J1, EJ1, EJ2 y C4, por citar algunos) o la presencia de asa (L5, L15, L16, O3, O4, V1, V2 y F1) o pie (L3) como elementos definitorios de un tipo: "se trata de ollas obligatoriamente decoradas" (Alcorta, 2001: 100); "aunque la presencia de la decoración solo ha sido comprobada en dos de los 
fragmentos de esta serie, es casi seguro que estamos ante un tipo obligatoriamente decorado" (Alcorta, 2001: 227), por citar algunos de los numerosos ejemplos (Alcorta, 2001: $105,114,207,226,234,240,250$ y 280). Esto dificulta mucho las tareas de clasificación. Además, algunas de las formas más representadas (O1, O2, O10, F1, EP1, EP3 y P1) tienen una adscripción cronológica muy amplia (s. II al v d. C.), mientras que muchos de los tipos del grupo de la cerámica común romana establecen su cronología en función de su documentación junto con ciertos tipos de la terra sigillata en contextos "revueltos» o «de dudosa datación» (Alcorta, 2001: 221-222, 232, 236, 239, 253, 278-279, 331 y 336 ).

Respecto a la cerámica de tradición indígena, pocos son los trabajos pormenorizados que se han llevado a cabo sobre esta producción o conjunto de producciones en Galicia (Rey, 1991; Fernández, 2008), y en ellos no se establecen tipologías claras que poder aplicar a las producciones estudiadas; además, presentan características morfotecnológicas y decorativas diferenciadas respecto a las seleccionadas para este trabajo, por lo que apenas podrán ser usadas como marco de referencia en nuestro estudio.

Todos estos problemas han suscitado que las producciones de este tipo, que son muy numerosas y complejas en el noroeste, hayan sido sistemáticamente ignoradas a lo largo de las décadas, lo cual ha provocado muchas dificultades a la hora de identificar tipos cuando aparecen y de diferenciarlos de otras producciones. Este trabajo forma parte de un primer intento de caracterización y delimitación de estas cerámicas en los castros del entorno de la ciudad de Lugo.

\section{Localización y características del yacimiento}

El castro de Agra dos Castros (fig. 1) se encuentra situado en el núcleo rural de Marcelle, concretamente en la zona denominada A Agra dos Castros (coordenadas ETRS89: huso

Figura 1. Localización del castro de Agra dos Castros.

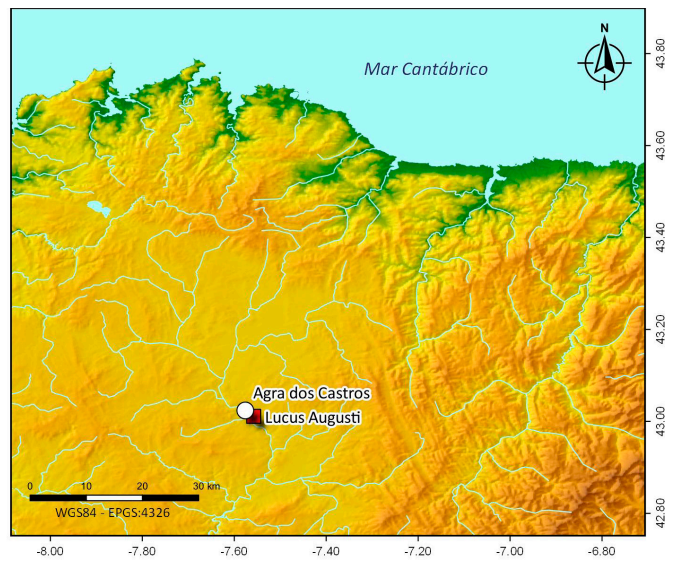




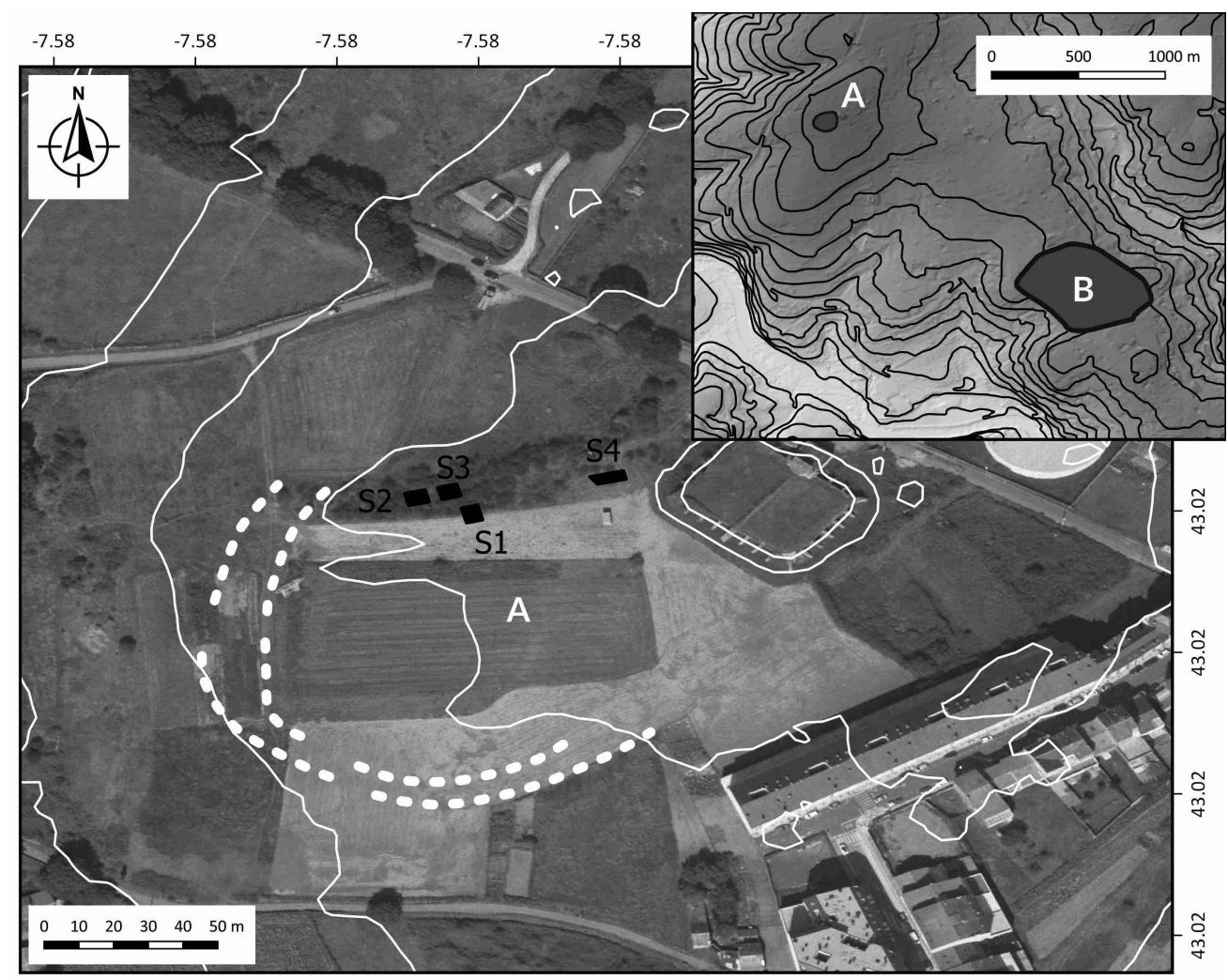

Figura 2. Mapa del castro de Agra dos Castros. A: Castro de Agra dos Castros; B: Lucus Augusti; S1 a S4: sondeos realizados.

UTM 29, X 616 015, Y 4764 467). Está ubicado 1 km al este del río Miño y a unos 1.500 m al sudeste de la antigua Lucus Augusti.

Las obras de control arqueológico llevadas a cabo para la instalación de la red de gasificación de Lugo en 1996 propiciaron la aparición de restos arqueológicos en el lugar. Posteriormente, entre 2007 y 2008, la construcción de una nueva zanja sin control arqueológico dejó al descubierto nuevos restos, lo que motivó la realización de una intervención. Hasta la fecha han sido documentados seis fosos, dos hacia el oeste y cuatro en el lado este, y varios parapetos de tierra entre el foso 1 y 2 (Bartolomé, 2008a: 31). Los sondeos, de aproximadamente $25 \mathrm{~m}^{2}$ cada uno, están situados en diferentes puntos del yacimiento, no muy alejados unos de otros (fig. 2). El primero se localiza al sur de la zanja y los otros dos, separados por escasos metros, se encuentran al norte de la misma. En base a los resultados obtenidos se realizó un cuarto sondeo, situado al oeste del foso l (fig. 2), para ampliar la intervención hacia el este, donde la zanja se había interrumpido, y así delimitar el trazado de esta. 
En los primeros trabajos realizados sobre el yacimiento (Bartolomé, 2008a, 2009) se establecieron las primeras valoraciones sobre el lugar, delimitando una primera fase prerromana (Bartolomé, 2008a: 30-31), a la que corresponden los elementos defensivos del castro junto con agujeros de poste con calzos, canales y fondos de cabaña. Los investigadores asocian a esta fase una arracada de oro «... hallada en un depósito de sedimentación formado por las diferentes labores agrícolas y remociones realizadas en la superficie del yacimiento, en los niveles inmediatamente superiores al nivel de abandono de época romana localizado» (Bartolomé, 2008b: 30-31).

A continuación, se describe una fase julio-claudia en la que se documentaron estructuras murarias (Bartolomé, 2008a: 32) junto con un denario de Tiberio (Bartolomé, 2008a: 32). La siguiente fase constructiva, que es la predominante, abarcará el período flavio hasta el siglo III d. C. y, asociados a ella, se localizaron estructuras murarias y pavimentos de arcilla (Bartolomé, 2008a: 32), desapareciendo en estos niveles los agujeros de poste. La mayoría de los materiales recuperados durante la excavación están asociados a estos niveles. Finalmente se documentó una última fase con restos de dos muros en mal estado de conservación, casi a nivel superficial, sin niveles de ocupación asociados (Bartolomé, 2008a: 33). En estas primeras valoraciones se apunta a una amplia ocupación estipulada en el yacimiento desde la Edad del Hierro, especialmente a partir del siglo IV a. C., hasta época bajoimperial (Bartolomé, 2009: 139 y 141).

\section{Metodología}

A través del análisis de las distintas producciones de cerámica común registradas en los cuatro sondeos del yacimiento, hemos intentado establecer la secuencia evolutiva de las mismas y asociarlas a momentos cronológicos, apoyándonos en los datos estratigráficos y en estudios comparativos con cerámicas de zonas afines como la ciudad de Lugo (Alcorta, 2001), otros castros de la costa lucense (Ramil et al., 1995; Lozano et al., 2015) o del occidente asturiano (Hevia et al., 1999, 2009). El objetivo primero era la caracterización de las producciones de cerámica presentes en el mismo, lo que nos permitiría profundizar en la secuencia cronológica del yacimiento y analizar su relación e influencia con la ciudad de Lucus Augusti. Sin embargo, la documentación administrativa a la que tuvimos acceso no recogía la totalidad del registro estratigráfico de estos cuatro sondeos, faltándonos información acerca de la localización de las unidades estratigráficas, que nos hubiera permitido asociar todos los materiales estudiados a paquetes estratigráficos. Finalmente, el estudio de estos materiales se realizó desde una perspectiva tipológica, intentando diferenciar producciones y asignando tipos que pudieran ayudarnos a profundizar en el conocimiento de estas producciones y a entender estas fases establecidas previamente.

Para realizar este estudio, hemos empleado una metodología clásica ya desglosada en otros trabajos (Barbazán et al., 2018: 171), restringiéndonos al estudio de la cerámica 
común ya que, por su cotidianeidad, es la que más datos puede aportar acerca de los cambios que se pudieron dar en este territorio. Entendemos como cerámica común todas aquellas producciones que, independientemente de las técnicas implementadas para su elaboración o la función y uso que pudieran haber tenido, no encajan dentro de otras producciones que cuentan con su propia idiosincrasia y estudios tipológicos, como la terra sigillata o las paredes finas.

Dentro de esta definición genérica de cerámica común, se han podido diferenciar varios conjuntos. En primer lugar, agrupamos varias producciones comúnmente englobadas bajo el nombre de "cerámica común romana», que, con gran imprecisión (Huguet, 2013: 293), se puede definir como la cerámica común que muestra las técnicas y formas importadas por los romanos tras la conquista y que no se puede encajar dentro de las otras producciones romanas conocidas. Suele estar caracterizada por una gran variabilidad formal y tecnológica. Está compuesta por cerámicas comúnmente englobadas dentro del servicio de cocina o de mesa, aunque también se incluyen cerámicas destinadas a almacenar, como los dolia, producciones como los morteros, los platos que imitan a los recipientes de engobe rojo pompeyano y las imitaciones o importaciones de época tardía. A nivel tecnológico es un conjunto muy heterogéneo, predominando el torno rápido sobre otras técnicas de elaboración, con pastas que presentan gran variedad cromática en superficie y que, dependiendo del tipo o grupo formal, tendrá una factura más o menos cuidada.

Dentro de la cerámica común existe otra producción que parece de elaboración local o regional y que a menudo ha sido puesta en relación con la cerámica anterior a la conquista (Maya, 1988: 153). A lo largo de esta investigación la denominaremos de manera genérica como «cerámica común de tradición indígena», para no generar una mayor confusión terminológica dentro del marco de los estudios cerámicos. Sus marcos cronológicos no están claros, pero se sugiere que comienza a elaborarse a lo largo de la Edad del Hierro (Maya, 1988; Rey, 1991) y continúa durante la época romana. Asimismo, sus marcos geográficos no están del todo definidos, situándose en la actual Galicia (Hidalgo y Rodríguez, 1987; Rey, 1991; Concheiro, 2008), el norte de Portugal (Martins, 1987; Silva, 1997), la zona de El Bierzo, León y Zamora (Esparza, 1987; Carretero, 2000) y Asturias (Maya, 1988; Maya y Cuesta, 2001).

Esta producción se diferencia de la cerámica común romana en que suelen ser recipientes hechos a mano o a torno lento, con pastas negras, grises o marrones que muestran abundantes desgrasantes de mica y cuarzo. La cocción suele ser irregular, mostrando un mismo fragmento distintas estructuras cromáticas. La coloración de las superficies oscila entre marrón, naranja, ocre, negro o gris oscuro, presentando, en ocasiones, gris claro. El tratamiento de las superficies se hará con someros alisados, presentando a menudo acabados más cuidados y existiendo, en ocasiones, un bruñido continuo.

A pesar de que existe una gran homogeneidad morfotecnológica en casi toda la cerámica de tradición indígena, dentro de esta producción separamos un subgrupo que difiere ligeramente. Aquí se han incluido tanto las piezas que presentan formas propias de la cerá- 
mica común de tradición indígena ejecutadas con técnicas romanas, como las que presentan formas que veremos después en la cerámica romana elaboradas con técnicas y decoraciones propias del sustrato indígena. Esta producción también ha recibido distintos nombres por parte de los investigadores (Arias, 1985; Alcorta, 2001; Hevia y Montes, 2009). Se ha decidido denominarla simplemente "cerámica común altoimperial», acotándola como un subgrupo dentro de la cerámica común de tradición indígena que se ha puesto a menudo en relación con tipos y formas cronológicamente situados en el siglo i d. C. Estas piezas presentan pastas oscuras con menor presencia de desgrasantes que el resto de la cerámica de tradición indígena y unos tratamientos superficiales más cuidados con exhaustivos bruñidos y cepillados.

\section{Estudio de los materiales}

\section{Cerámica de tradición indígena de Agra dos Castros}

Las ollas son el grupo mayoritario en la cerámica de tradición indígena dentro de los sondeos analizados. En este conjunto diferenciamos varios grupos formales. Tenemos un primer grupo (fig. 3), en el que englobamos la mayoría de las ollas documentadas: piezas de labio plano o redondeado, borde oblicuo, cóncavo o recto y cuerpo que parece derivar en una línea convexa. Dentro de este conjunto destaca un subgrupo de ollitas de dimensiones pequeñas (fig. 3: 1), algunas de las cuales adscribimos dentro del L14 de Lugo (Alcorta, 2001: 115).

En menor medida se ha podido identificar un segundo grupo formal (fig. 3: 8), con piezas de labio redondeado, borde oblicuo de corto desarrollo y cuerpo de línea compleja oblicua convexa.

Tenemos un tercer grupo (fig. 4: 7 y 8) que difiere en cuanto a forma y decoración. Presenta borde y cuerpo convexo, labio plano, facetado en la cara interna del borde y una decoración en la cara externa del borde a base de una sucesión de impresiones de un cuerpo hueco de sección semicircular (fig. 4: 7). Destacan dos piezas con distinta decoración (fig. 4: 8), presentando en la cara externa del borde una sucesión horizontal de líneas oblicuas incisas abiertas y cerradas y bandas oblicuas de pequeñas incisiones de forma rectangular en la cara externa del cuerpo.

También hemos diferenciado un pequeño conjunto de piezas (fig. $4: 1$ y 2) que constituye un cuarto grupo formal de ollas de labio redondeado, borde cóncavo de corto desarrollo y cuerpo que parece desarrollarse a través de una línea convexa poco marcada, una de las cuales (fig. 4: 2) presenta decoración a base de líneas acanaladas horizontales y un cepillado en la cara externa del borde.

Hemos podido identificar un fragmento de borde oblicuo con un orificio circular que lo atraviesa en su parte central (fig. 4: 3) y que se trata del único ejemplo de olla L10 

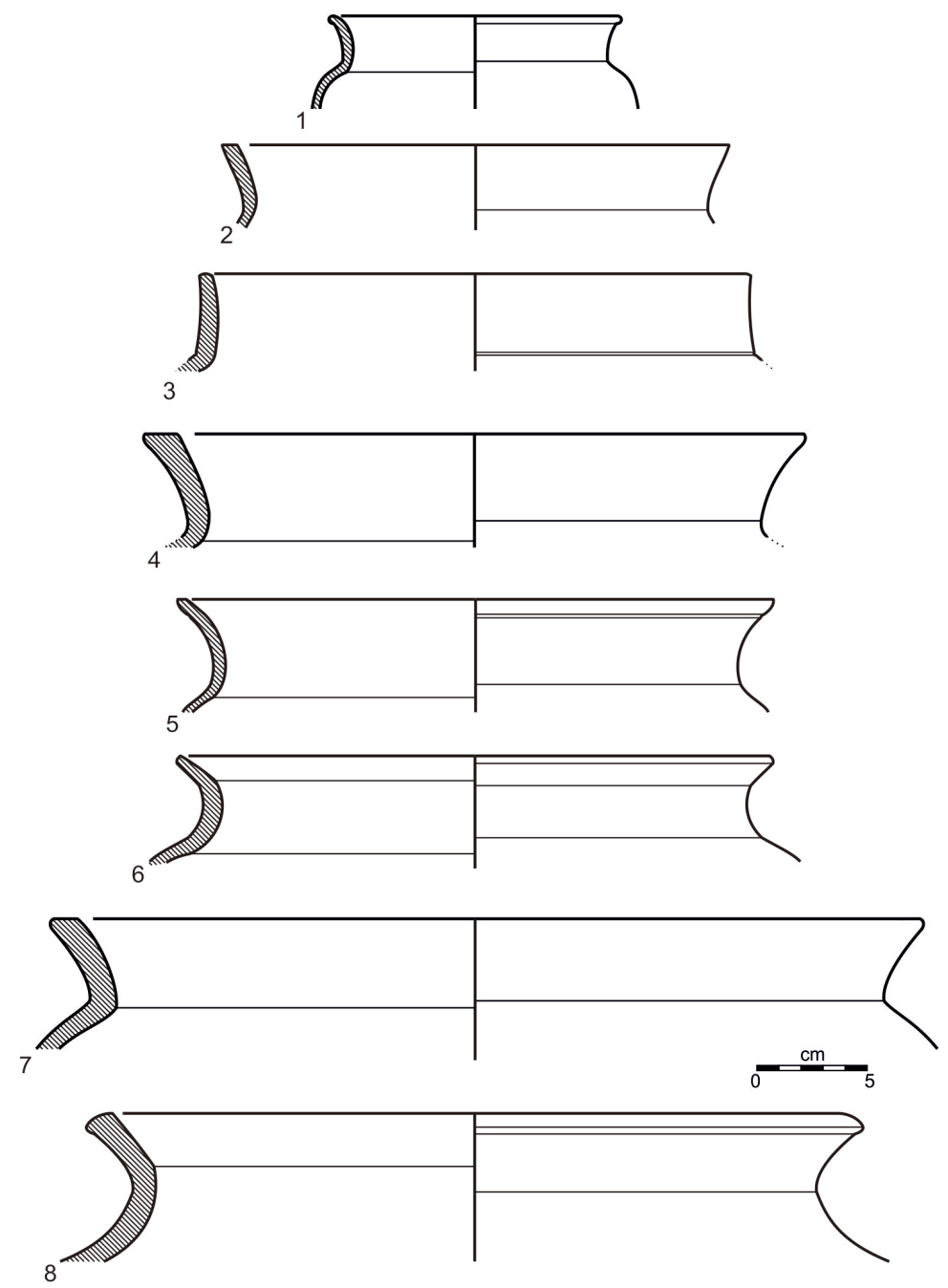

Figura 3. Cerámica común de tradición indígena. Ollas (1-13).

(Alcorta, 2001: 109) u olla de orejeta perforada. El escaso desarrollo de su perfil impide decir más sobre el desarrollo de su forma o sus diámetros.

Documentamos varias piezas de difícil adscripción, cuyo escaso desarrollo del perfil no nos ha permitido asignarlas a ninguna forma conocida. La primera presenta un borde oblicuo de escaso desarrollo, seguido de un cuello o cuerpo oblicuo con decoración de líneas incisas oblicuas en su cara externa (fig. 4: 6). La segunda (fig. 4: 5) tiene borde oblicuo cerrado con labio redondeado, seguido por un cuerpo convexo que presenta una 

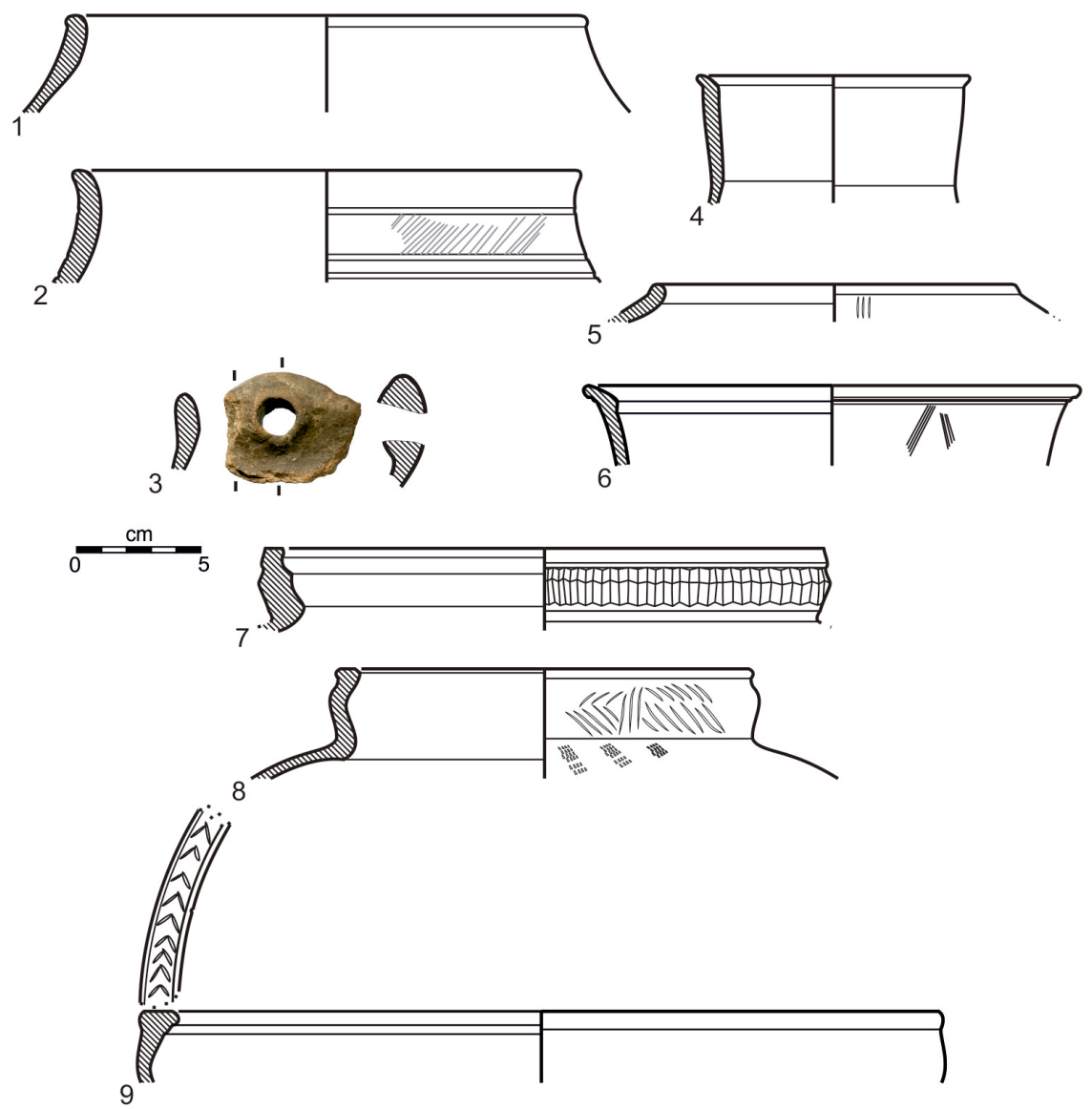

Figura 4. Cerámica común de tradición indígena. Ollas (1-3, 7 y 8), cuenco (9) y otros (4-6).

decoración de tres pequeñas líneas incisas rectas paralelas verticales en la inflexión entre el cuello y el cuerpo. En último lugar estaría un recipiente que podría incluirse dentro del grupo de las jarras, dadas sus características morfológicas (fig. 4: 4), que presenta un pequeño borde oblicuo de labio redondeado, seguido por un cuello recto del que parte un cuerpo que parece convexo.

El siguiente conjunto documentado en la cerámica de tradición indígena es el de los cuencos (fig. 4: 9), aunque su representación será muy escasa en todos los sondeos analizados. Se trata de un pequeño conjunto de piezas de labio redondeado, borde con desplazamiento horizontal cerrado o bilateral y cuerpo convexo. Generalmente no muestran decoración, a excepción de un recipiente con líneas oblicuas incisas en la cara superior del labio que conforman un motivo espigado (fig. 4: 9). 

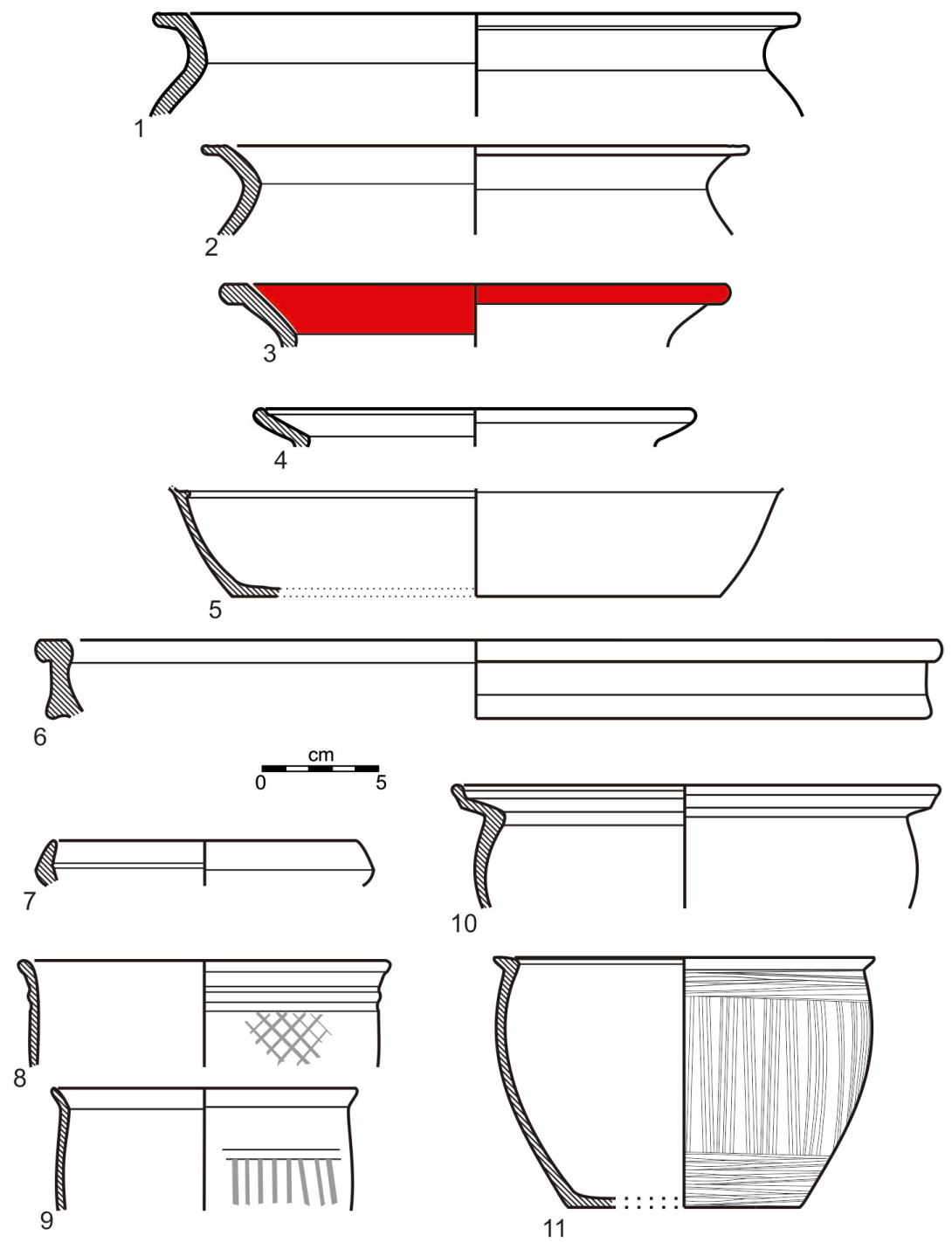

Figura 5. Cerámica común altoimperial. Ollas (1-4), plato (5), fuente (6), cuencos (7), vasos (8 y 9) y cazuelas (10 y 11$)$

Dentro de esta producción diferenciamos un subgrupo que presenta una morfotecnología algo diferente, la cerámica común altoimperial (fig. 5), donde destaca un conjunto de ollas (fig. 5: 1 y 2) asociadas a las Ll de Lugo (Alcorta, 2001: 81). Aunque no hemos podido constatar si poseen la decoración que caracteriza a las L1, son muy similares a las ollas lisas de borde facetado del Chao Samartín, también asociadas por otros investigadores 
a este grupo de Lugo (Hevia y Montes, 2009: 89). Dentro de este conjunto hemos diferenciado un par de recipientes (fig. 5: 3) que presentan un engobe rojo en la cara interna del borde y en la zona del labio, que recuerdan vagamente a las ollas de fabricación regional altoimperial engobadas que se han registrado también en el castro del Chao Samartín (Hevia y Montes, 2009: 71) o a las «ollas tempranas engobadas» de Lugo (Alcorta, 2005c).

Dentro de este subgrupo hemos identificado un pequeño conjunto de cuencos (fig. 5: 7) asimilables a los L12 de Lugo (Alcorta, 2001: 111) y una fuente (fig. 5: 6) con labio redondeado y un pequeño borde con desplazamiento horizontal abierto, seguido de un cuerpo convexo oblicuo abierto en el que resalta la presencia de una pequeña visera oblicua de sección triangular, para la que no hemos encontrado paralelos. También documentamos un plato (fig. 5: 5), con una pequeña visera en la parte interna del cuerpo, que se adscribe dentro del L17 de Lugo (Alcorta, 2001: 124).

Otro conjunto (fig. 5: 8 y 9) que situamos dentro de este subgrupo es el de los vasos L16 (Alcorta, 2001: 122), con una característica decoración en forma de líneas acanaladas horizontales y bruñidas oblicuas o rectas.

Identificamos un recipiente (fig. 5: 10) con características muy similares a las descritas para las "cazuelas hondas de fondo plano" documentadas en el Chao Samartín (Hevia y Montes, 2009: 75), para el que no hemos encontrado paralelos dentro de las formas lucenses. En la misma línea se documentó otro (fig. 5: 11) que se asemeja a las «cazuelas troncocónicas» también documentadas en el Chao Samartín (Hevia y Montes, 2009: 28). Este recipiente presenta cierta similitud con un vaso carenado altoimperial de Lugo (Alcorta, 2001: 121), pero el escaso desarrollo del perfil del recipiente lucense no permite establecer una relación.

En último lugar hemos documentado dos piezas de difícil adscripción (fig. 5: 4). Presentan un borde oblicuo, con un ligero rehundimiento en la cara interna. Su morfología recuerda a diversas formas como las ollas L5 (Alcorta, 2001: 97) o algunas variantes dentro de las ollas L1, como las Llc, pero debido al pequeño desarrollo de las piezas no podemos aseverar dentro de cuál.

\section{Cerámica común romana de Agra dos Castros}

Dentro de la cerámica común romana de este yacimiento, el grupo mejor documentado es el de las ollas, seguido de cerca por las fuentes. En las ollas abundan los recipientes de cuerpo convexo, sin cuello y con un borde cóncavo u oblicuo, adscritos a las Ol (fig. 6: 1), $\mathrm{O} 2$ (fig. 6: 2 y 3), O24 (fig. 6: 4), O5 (fig. 6: 5) y O6 (fig. 6: 8) de Lugo (Alcorta, 2001: 193198, 202-207 y 250). Carecen de decoración, exceptuando los recipientes O5 y O6, que muestran líneas horizontales rectas u onduladas acanaladas en la cara externa del cuerpo. Dentro de este grupo hemos documentado recipientes de grandes dimensiones (fig. 6: 9) que, aunque guardan similitudes con las ollas O12 de Lugo, no presentan el suficiente desarrollo del perfil como para saber si poseen la decoración espatulada, característica obli- 
gatoria para la definición de este tipo: "grandes ollas globulares, grises, de borde exvasado y decoración espatulada [...], decoración de obligada presencia y concentrada en un único campo enmarcado entre juegos de acanaladuras situado en la parte superior de la panza, sin rebasar el diámetro máximo» (Alcorta, 2001: 223 y 226).

También hemos registrado un conjunto de piezas (fig. 6: 6) que, aunque tienen características formales muy similares a las jarras Jl de Lugo (Alcorta, 2001: 279), su factura tosca y las marcas de exposición al fuego las acercan a las características descritas para las ollas de cocina O3 (Alcorta, 2001: 199).

Hemos documentado dos piezas (fig. 6: 7) de labio redondeado, borde con desplazamiento horizontal abierto y cuerpo convexo. Su morfología recuerda vagamente a recipientes documentados dentro de algunas ollas de importación tipo «CNT» (Aguarod, 2017: 48, fig. 14: 3 y 8), si bien difieren en sus pastas, que no coinciden con las descritas para este tipo y, tecnológicamente, son muy similares al resto de las ollas romanas documentadas.

El segundo grupo formal con mayor representación es el de las fuentes con visera (fig. 7: 1-4). Estas fuentes se relacionan con las F1, consideradas como la continuación de las L19 del siglo i d. C. en Lugo (Alcorta, 2001: 341). Hemos documentado algunas piezas con líneas rectas horizontales acanaladas bajo el labio o en la cara externa del cuerpo y una pieza (fig. 7: 3) que presenta líneas acanaladas rectas y onduladas en la cara interna del cuerpo. Dentro del grupo de los platos, también hemos identificado un conjunto de platos grises P1 (fig. 7: 6 y 7) y un par de piezas con un denso engobe rojo en la cara interna del cuerpo relacionado con los EPl (fig. 7: 5), o platos de imitación de engobe rojo pompeyano (Lapuente et al., 1996; Alcorta, 2001: 344).

Documentamos dos piezas con dimensiones bastante homogéneas que presentan un desarrollo formal muy similar al de los platos (fig. 7: 8), con la diferencia de la presencia de una visera oblicua de sección triangular en la parte superior del cuerpo. Esta característica recuerda a la visera presente en los C5 de Lugo (Alcorta, 2001: 335-336); además, los recipientes estudiados coinciden con las características de pastas, desgrasantes y tratamiento superficial indicadas para los C5, si bien difieren demasiado morfológicamente como para incluirlos en este grupo.

En el grupo de los cuencos, escasamente representado, se ha identificado una pieza (fig. 8: 1) con engobe en la superficie interna del cuerpo, adscribible a los EC1 de Lugo (Alcorta, 2001: 325).

También hemos documentado dos piezas que se asemejan en su forma a este grupo de los cuencos. La primera (fig. 8: 2) presenta un desarrollo formal muy difuso del que solo conservamos el que parece ser el borde convexo, con dos líneas rectas horizontales y paralelas acanaladas en la cara externa del mismo. De continuar el perfil convexo del cuerpo, este recipiente podría tratarse de un cuenco C2 (Alcorta, 2001: 329-330), pero no podemos asegurarlo debido al escaso desarrollo de la pieza. A esto se le suma una extraña factura, pues presenta unas pastas grises muy claras de textura granulosa, con un gran deterioro superficial que nos impide saber cuál era su tratamiento superficial. La segunda pieza (fig. 8: 3), que presenta labio redondeado y cuerpo convexo con una ligera carena, 

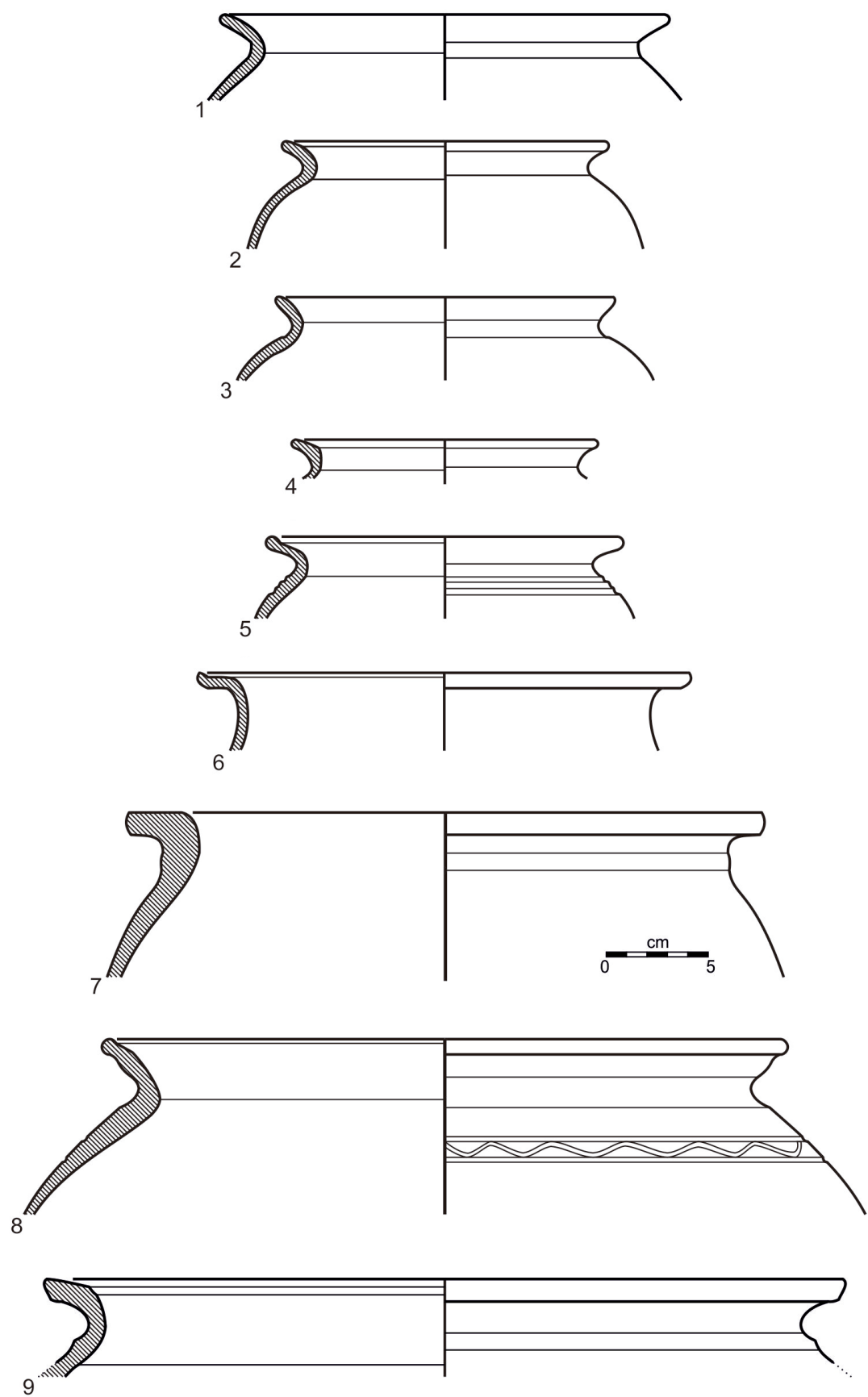

Figura 6. Cerámica común romana. Ollas (1-9). 

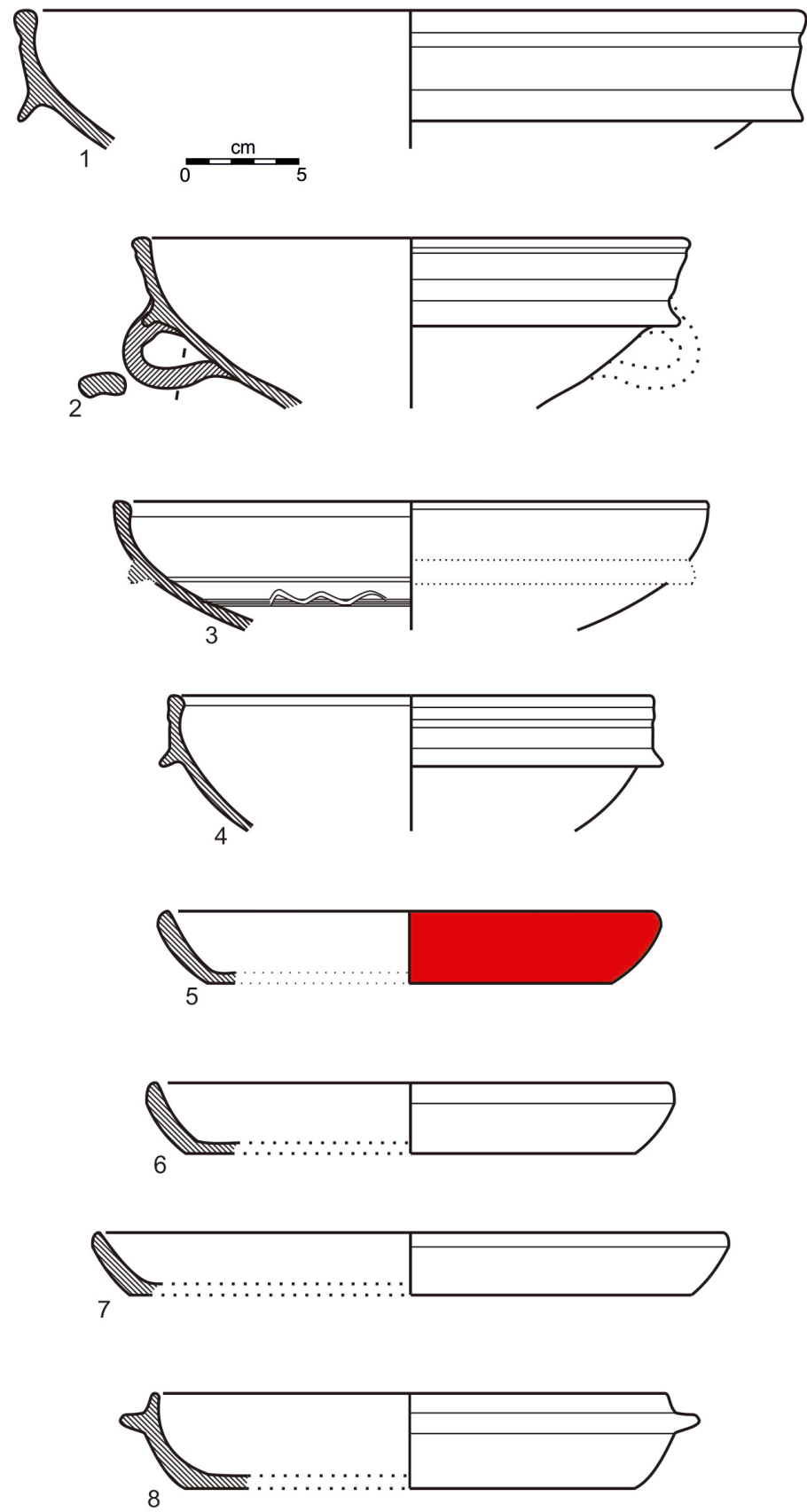

Figura 7. Cerámica común romana. Fuentes (1-4), platos (5-7) y otros (8). 

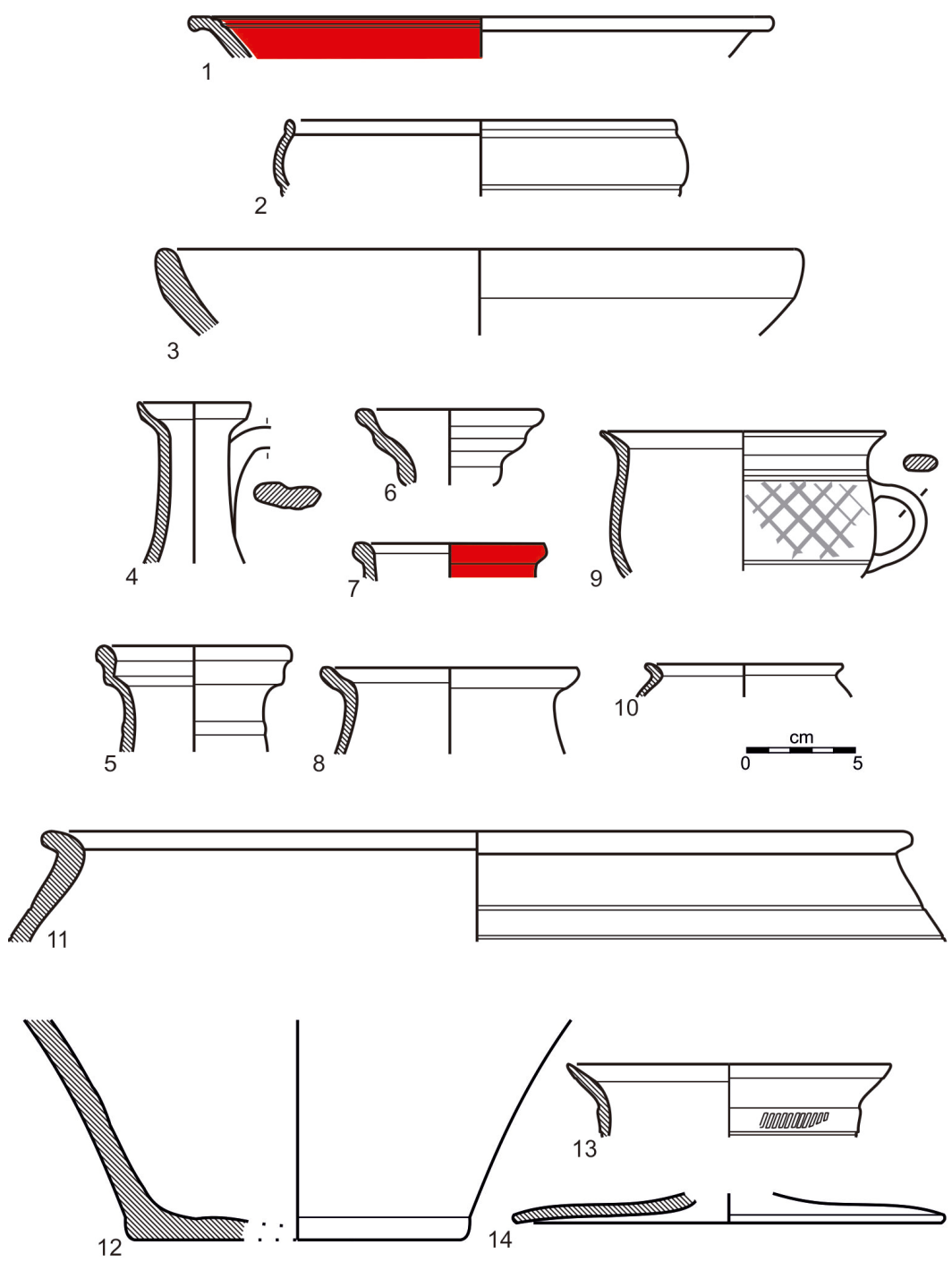

Figura 8. Cerámica común romana. Cuencos (1-3), jarras (4-8), vasos (9-10) y otros (11-14).

podría tratarse de un plato Pl, pero su morfología, grosor y pastas difieren de las referenciadas para este tipo.

Hemos documentado bordes de muy pequeñas dimensiones que recuerdan a los bordes de las jarras. Dentro de este grupo, identificamos dos recipientes (fig. 8: 5-7) que se asemejan a las EJ1 de Lugo (Alcorta, 2001: 295), y otro (fig. 8: 4) a las EJ2 (Alcorta, 2001: 297), pero no han conservado su engobe superficial. También identificamos un conjun- 
to (fig. 8: 8), que adscribimos dentro de las Jl de Lugo (Alcorta, 2001: 279). Como en casos anteriores, el escaso desarrollo del perfil hace que pueda encajar morfológicamente también dentro de las ollas $\mathrm{O} 3$, si bien las englobamos dentro del grupo de las jarras por presentar una factura más cuidada, tal y como corresponde a este grupo.

Tenemos un par de piezas (fig. 8: 9) adscritas dentro de los V1 de Lugo (Alcorta, 2001: 260). Presentan una decoración con líneas oblicuas bruñidas en la cara externa del cuerpo que forman un motivo reticulado que se encuentra enmarcado dentro de dos grupos de líneas acanaladas horizontales. Asimismo, se ha documentado un pequeño recipiente (fig. 8: 10) que enmarcamos dentro de los vasos V3 de Alcorta (2001: 271).

Agrupamos aparte dos piezas de grandes dimensiones y morfología diversa que podrían relacionarse con el conjunto de los dolia o vasijas de almacenamiento (fig. 8: 11), documentando también una pieza de cuerpo y base de grandes dimensiones (fig. 8: 12) que se corresponde con un TR (Alcorta, 2001: 300) de Lugo. Asimismo, documentamos varios fragmentos de tapadera (fig. 8: 14) de labio redondeado y cuerpo cóncavo u oblicuo, identificables como tapaderas T1 de Lugo (Alcorta, 2001: 256).

En último lugar tenemos un recipiente (fig. 8: 13) de labio redondeado, borde oblicuo y cuello recto, con una banda plástica horizontal en la cara externa del cuello, decorada con líneas incisas oblicuas paralelas. Esta pieza está fabricada con pastas sienas de abundantes desgrasantes micáceos, semejante a los recipientes I29 de Lugo (Alcorta, 2001: 131), que imitan la forma 29 de la TSG. También guarda semejanzas con la forma 29 de la TSH (López, 2007: 241, fig. 27.60).

\section{Los materiales y su cronología}

A excepción del último sondeo, en el que la cerámica de tradición indígena se documenta de manera prácticamente mayoritaria, y el sondeo 1, donde la cerámica común romana despunta ligeramente sobre la de tradición indígena, los otros dos sondeos no muestran un predominio claro de ninguna producción sobre otra.

Respecto a las características de la cerámica de tradición indígena, ésta muestra una morfotecnología muy homogénea y una escasa variedad tipológica (fig. 9: 1-3). Principalmente se documentan ollas de borde recto, oblicuo o cóncavo con cuerpo convexo, cuya presencia en la totalidad de la muestra es casi igual a la de las ollas de producción romana, lo cual indica que pudieron complementarse. Dentro de esta producción también se identifican algunos cuencos, pero de manera muy marginal. Estas piezas tienen características muy similares a las analizadas en otros asentamientos de la zona, como Punta do Castro (Lozano et al., 2015), el castro de Viladonga (Barbazán et al., 2018) y el castro de Zoñán (Vigo, 2007), todos de época romana, diferenciándose en sus características tecnológicas de cerámicas de tradición indígena más antiguas documentadas en sitios como el castro de Vixil (Ramil, 1997). 

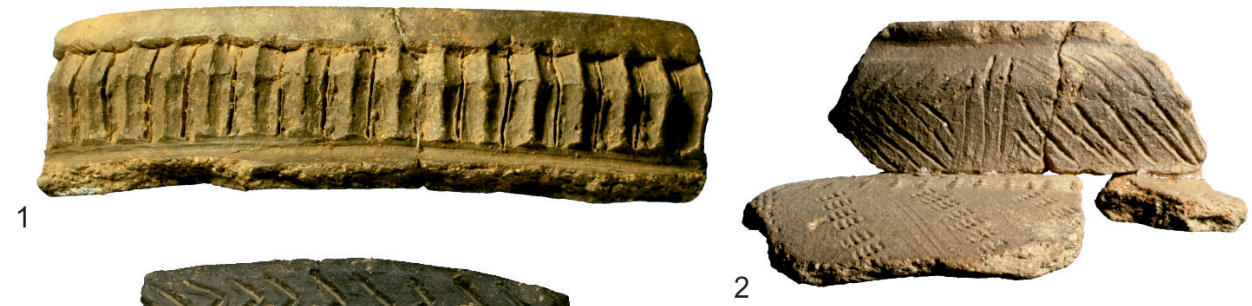

3

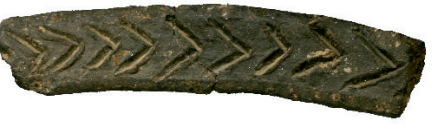

2
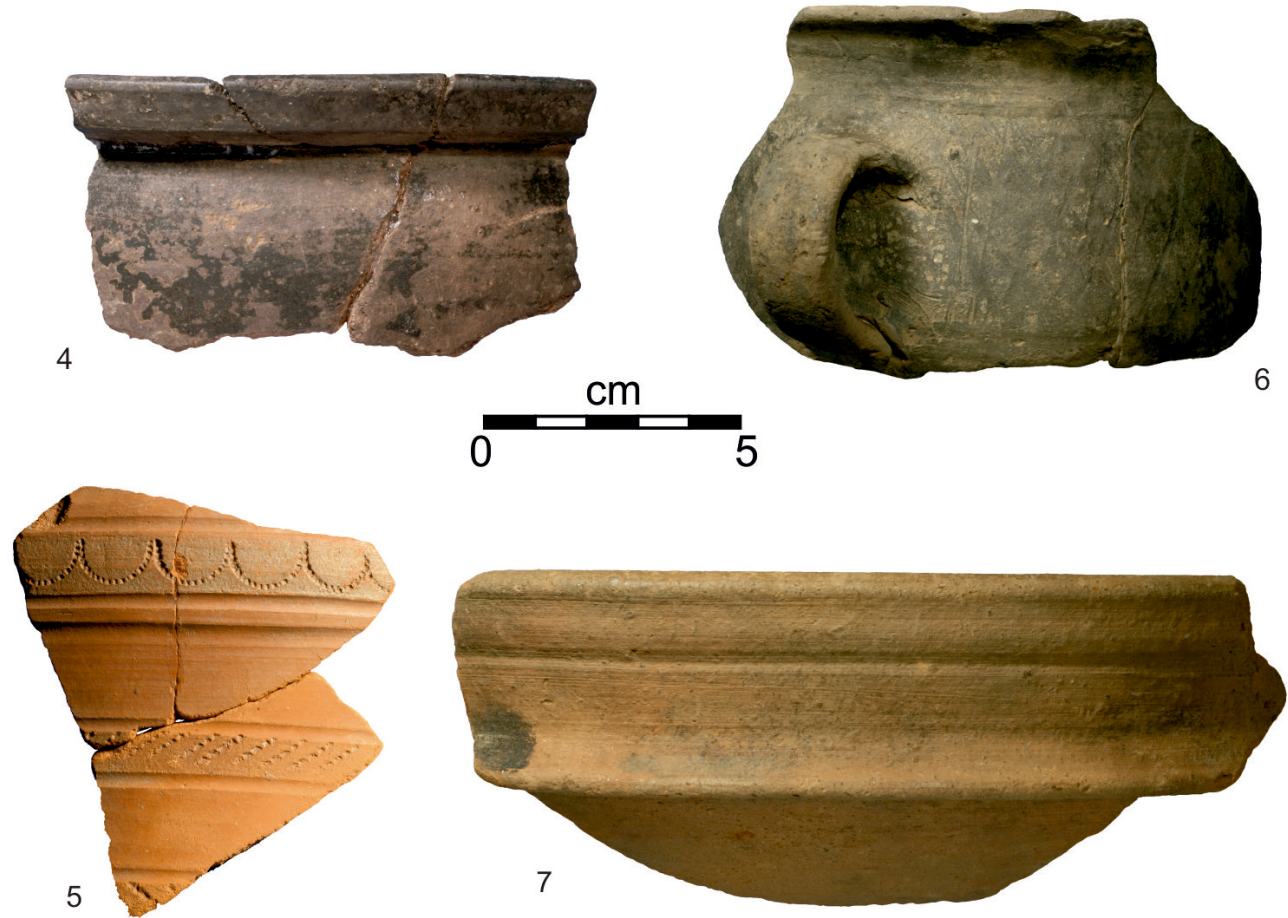

Figura 9. Cerámica de Agra dos Castros. Cerámica de tradición indígena (1-3), altoimperial (4-5) y común romana (6-7).

El subgrupo altoimperial (fig. 9: 4-5) se identifica de manera predominante dentro de la cerámica de tradición indígena, siendo significativa la presencia de ollas de borde facetado, que en ocasiones serán mayoría respecto a las ollas de tradición indígena, pudiendo unas sustituir a otras con el paso del tiempo y el cambio en los gustos de consumo. De especial importancia es la identificación de la "cazuela honda de fondo plano» y de «la cazuela troncocónica», cuyo paralelo más inmediato se encuentra en la Asturias occidental. Su ausencia hasta el momento quizás pueda explicarse por la falta de información acerca de los niveles más antiguos de la ciudad de Lugo. 
Estos materiales pueden delimitar un poco más la cronología del yacimiento, como las ollas de borde facetado, presentes en el Chao Samartín en los siglos I y il d. C. (Hevia y Montes, 2009: 88); las cazuelas, también presentes en el Chao Samartín en el siglo I d. C. (Hevia y Montes, 2009: 77-78), y los vasos L16, los cuencos L12, el plato L17 y las ollas de Lugo (Alcorta, 2001: 109, 111 y 124-125), con una cronología que los sitúa en el siglo I d. C.

En las producciones de la cerámica común romana (fig. 9: 6-7) destaca, como suele ser habitual, el conjunto de las ollas de cocina. En mucha menor medida se documentan otras formas como vasos, cuencos, jarras, platos y un par de tapaderas. Llama la atención en este yacimiento la fuerte presencia de fuentes tipo Fl (Bartolomé, 2009: 157) (fig. 9: 7), que se identifican casi en igual medida que las ollas, algo que no es habitual y para lo que no tenemos explicación más allá de que procedan de una zona en la que se realice alguna actividad específica que las precise, algo que no podremos contrastar hasta que no se amplíe la intervención sobre el yacimiento.

La mayoría de los recipientes romanos identificados tienen una cronología muy amplia, abarcando del siglo II al v d. C. (Alcorta, 2001: 196-197, 256, 341, 344 y 359), aunque contamos con piezas que permiten una mayor precisión, como las ollas O24 o el EC1, que van del siglo II al IV (Alcorta, 2001: 252 y 325); los V1, que se encuentran situados del I al III d. C. (Alcorta, 2001: 264); los V3, del i al II (Alcorta, 2001: 271); las J1, entre el II y el III (Alcorta, 2001: 280), y el I29, acotado en Lugo entre la tercera y cuarta década de la primera centuria (Alcorta, 2001: 132).

Hay que subrayar la escasez de piezas de marcado carácter tardío, es decir, cerámicas que tengan su origen ya en época avanzada dentro de la cronología romana, con tan solo algunas ollas $\mathrm{O} 5$ documentadas y un solo ejemplar de olla O6, situadas dentro del siglo IV-V d. C. (Alcorta, 2001: 202-207). Esta escasez de piezas bajoimperiales, junto con la fuerte presencia de recipientes altoimperiales, pueden indicar una ocupación más significativa durante los primeros siglos del cambio de era.

Si complementamos esta información con los datos acerca de otros materiales que hemos extraído de los informes (Bartolomé, 2008b), nos encontramos con que restos que se han dado como antiguos, como la arracada de oro (Balseiro y Bartolomé, 2018), y que se han asociado a este nivel prerromano, provienen del nivel superficial revuelto del sondeo 1, por lo que han sido recogidos fuera de contexto. La documentación de un denario de plata de Tiberio en un nivel sellado del sondeo 2, por sí sola, tampoco indica necesariamente la existencia de un nivel de ocupación de época julio-claudia, ya que se trata de un material que pudo seguir usándose a lo largo del tiempo y, por lo tanto, continuar en circulación más allá de esta época. Para sustentar la cronología de estos dos niveles, los investigadores (Bartolomé, 2008a, 2008b, 2009) también aluden a la presencia de cerámica indígena del siglo i d. C. Por un lado, como ya hemos reseñado, la mayoría de la cerámica documentada no aporta una cronología tan precisa y, por otro, su procedencia exacta no ha podido ser contrastada, ya que carecemos de la información estratigráfica que conecta los materiales estudiados con dichos niveles. Hay que destacar que en el sondeo 3 
también se documentó una lucerna de importación a la que se han referido como de origen bético (Bartolomé, 2008a: 32).

Según la documentación administrativa aportada por el investigador (Bartolomé, 2008 b), la terra sigillata documentada es, en su gran mayoría, TSH, con casi un centenar de piezas (Bartolomé, 2009: 155). La TSG se registra en mucha menor medida, con seis piezas recogidas en la documentación administrativa, aunque en trabajos posteriores se refieren a esta producción como «ausente» (Bartolomé, 2009: 155). La TSHT está presente en este sondeo con tan solo 10 piezas (Bartolomé, 2009: 158). Por último se ha identificado una pieza clasificada como TSAD tipo Hayes 58 (Bartolomé, 2009: 158).

Teniendo en cuenta los datos que aportan los materiales, resulta difícil secundar algunas de las hipótesis cronológicas establecidas de manera inicial para este yacimiento. La fase prerromana, establecida entre el siglo IV y el siglo II a. C. (Bartolomé, 2009: 141), se sustentaría en base a unos agujeros de poste y fondos de cabaña hechos con materiales perecederos, una arracada de oro documentada fuera de contexto en un revuelto superficial, la existencia de fosos y parapetos y la presencia exclusiva de cerámica de tradición indígena en determinados niveles. Dado que no se ha tenido acceso a la totalidad del registro estratigráfico y desconocemos de qué niveles proceden todos los materiales analizados, solo podemos afirmar que la cerámica de tradición indígena que se ha podido estudiar tiene características similares a la documentada en otros asentamientos cercanos adscritos a época romana, por lo que, por sí sola, no es prueba suficiente para sustentar una cronología tan específica para esta fase. Si nos ceñimos a los materiales analizados, lo cierto es que la mayoría de los recipientes identificados muestran una cronología demasiado amplia como para permitirnos ser tan precisos. A nivel general, la cerámica estudiada encaja dentro del arco cronológico dado para la mayoría de las estructuras de época romana que se sitúan dentro de la llamada fase flavia.

En un principio se podría perfilar un período amplio que va desde el siglo I al IV d. C., si bien este dato ha de tomarse con cautela, ya que no implica necesariamente una ocupación continuada del castro desde el siglo I d. C., sino que podría responder a la sucesión de distintas fases de ocupación dentro de ese largo período. Cabe mencionar que la mayoría de las piezas se sitúan entre los siglos I y II d. C., mostrando una clara incidencia en época altoimperial y siendo marginales las correspondientes a época bajoimperial.

\section{Conclusiones}

En este yacimiento, a priori de cronología altoimperial con posibles ocupaciones en épocas más tardías, la influencia de los núcleos romanizadores es bastante importante si tenemos en cuenta la información que nos aporta la cerámica. En Agra dos Castros se ha documentado una presencia significativa de producciones romanas y de piezas altoimperiales a lo largo de casi todos los sondeos estudiados, mientras que la cerámica de tradición 
indígena se reducirá a unas cuantas ollas, no registrándose apenas otras formas que sí se documentan en gran medida en otros castros del entorno, como los cuencos (Barbazán et al., 2018). La realidad que se refleja en el castro es la de una dependencia o gusto mayor por las nuevas formas romanas, constatando una preferencia importante por los recipientes del subgrupo altoimperial.

Este subgrupo, que prueba la creciente hibridación de ambas tradiciones, será aquí especialmente significativo, con formas no documentadas en la zona previamente como las cazuelas de Asturias y una gran variabilidad formal y tipológica. Esta influencia se debe principalmente a la proximidad del castro respecto a la ciudad romana, lo que posibilita una mayor accesibilidad a las nuevas producciones que se estaban introduciendo en los primeros siglos después del cambio de era. Todo esto muestra que, lejos de que una tradición sustituya a la otra o la elimine, ambas se complementan, aumentando el conjunto a lo largo del siglo i y II d. C.

\section{Bibliografía}

AGUAROD, C., 2017, Cerámica común de mesa y de cocina en el valle del Ebro y producciones periféricas, en C. FERNÁNDEZ, M. ZARZALEJOS y A. MORILLO (eds.), Manual de cerámica romana III, 15-95.

ALARÇAO, J., 1975, Cerámica común local y regional de Conímbriga, Universidade de Coimbra, Oporto.

ALCORTA, E., 2001, Cerámica común romana de cocina y mesa hallada en las excavaciones de la ciudad, Fundación Barrié de la Maza, Lugo.

ALCORTA, E., 2005a, Lucus Augusti como centro de producción y consumo cerámico, en C. FERNÁNDEZ y P. GARCÍA (coords.), Unidad y diversidad en el arco atlántico en época romana. III Coloquio Internacional de Arqueología en Gijón, BAR International Series 1371, Oxford, 191-202.

ALCORTA, E., 2005b, Algunas notas en torno a la decoración de arquerías de la cerámica de tradición indígena hallada en Lucus Augusti, CROA 15, 37-44.

ALCORTA, E., 2005c, Anotaciones a las primeras vasijas engobadas tempranas, sobre cerámicas indígenas, de Lucus Augusti, Boletín do Museo Provincial de Lugo 12, 15-40.
ALCORTA, E., 2006, Memoria de resultados da escavación arqueolóxica do soar das rúas Amor Meilán, 5-7, Rúa Nova, 84 e Bolaño Ribadeneira, 18 de Lugo, Boletín do Museo Provincial de Lugo 13, 13-68.

ALCORTA, E. y BARTOLOMÉ, R. 2012, Muestras de cerámica engobada romana de producción local de Lucus Augusti (Lugo), en D. BERNAL y A. RIBERA I LACOMBA, (eds.), Cerámicas hispanorromanas II. Producciones regionales, Universidad de Cádiz, 699-724.

ALCORTA, E., BARTOLOMÉ, R. y FOLGUEIRA, A., 2014, Acercamiento a los modelos arquitectónicos, funcionales y productivos generales y de imitación de una ínsula alfarera en Lucus Augusti (Lugo), en R. MORAIS, A. FERNÁNDEZ y M. J. SOUSA (eds.), As produções cerâmicas de imitação na Hispania, Monografías EX OFFICINA HISPANA II, Oporto, 425-446.

ALCORTA, E., BARTOLOMÉ, R. y FOLGUEIRA, A., 2015, Producciones cerámicas engobadas lucenses y su distribución, en A. MARTÍNEZ, M. ESTEBAN y E. ALCORTA (eds.), Cerámicas de época romana en el norte de Hispania y en Aquitania. Producción, comercio y consumo entre el Duero y el 
Garona, EX OFFICINA HISPANA. Cuadernos de la SECAH 2, Bilbao, 77-96.

ALCORTA, E., BARTOLOMÉ, R. Y SANTAMARÍA, G., 2011, Un novo obradoiro de olería en Lucus Augusti. Resultados da escavación arqueolóxica en área da parte traseira do inmoble n. ${ }^{\circ} 8$ da rúa Quiroga Ballesteros de Lugo, Boletín do Museo Provincial de Lugo 14, 65-82.

ARIAS, F., 1985, Castro de Viladonga. Campaña 1983, Arqueoloxía/Memorias 2, Xunta de Galicia, Santiago de Compostela.

BALSEIRO, A. y BARTOLOMÉ, R., 2018, Arracada da Agra dos Castros, Boletín do Museo Provincial de Lugo 15, 15-31.

BARBAZÁN, S., 2019, La cerámica como factor de intercambio cultural en el proceso romanizador de Gallaecia, Tesis inédita, Santiago de Compostela.

BARBAZÁN, S., RAMIL, E. y LOZANO, H., 2018, La evolución cronológica del Castro de Viladonga (Castro de Rei, Lugo) a través del estudio de su cerámica común romana, BSAA arqueología LXXXIV, 168-214.

BARTOLOMÉ, R., 2008a, Primeiras valoracións da intervención realizada en Agra dos Castros, Marcelle (Lugo), CROA 18, 28-33.

BARTOLOMÉ, R., 2008b, Sondeos arqueológicos manuales en Agra dos Castros, Marcelle (Lugo), Informe valorativo inédito.

BARTOLOMÉ, R., 2009, O castro da Piringalla e a súa relación con Lucus Augusti, en M. D. DOPICO, M. VILLANUEVA, P. RODRÍGUEZ y X. R. CUBA (coords.), Do castro á cidade: a romanización na Gallaecia e na Hispania indoeuropea. Actas do curso de actualización sobre a romanización de Galiza, Lugo, 131-165.

BARTOLOMÉ, R., 2015, Marcas de alfarero sobre cerámica común romana de engobe rojo de producción lucense, Férvedes 8, Museo de Prehistoria e Arqueoloxía de Vilalba, Vilalba, 351-360.

BARTOLOMÉ, R. y LÓPEZ, C., 2015, Contextos de producción cerámica bajoimperial lucense: el ejemplo proporcionado en la excavación del solar n. ${ }^{\circ} 8$ de la calle Quiroga Ballesteros (Lugo),
Férvedes 8, Museo de Prehistoria e Arqueoloxía de Vilalba, Vilalba, 341-350.

CARRETERO, S., 2000, El campamento romano del Ala II Flavia en Rosinos de Vidriales (Zamora). La cerámica, Instituto de Estudios Zamoranos Florián de Ocampo, Zamora.

CONCHEIRO, A., 2008, Castro do Achadizo: cultura material, economía de subsistencia na Idade de Ferro. Memoria das escavacións 1991-1994, Concello de Boiro, Boiro.

DÍAZ, I. y GARÍN, A., 1999, Estudio de los materiales arqueológicos de Castro Ventosa, Estudios Bercianos 25, 74-95.

DELGADO, M., MORAIS, R. y RIBEIRO, J., 2009, Guia das cerâmicas de produção local de Bracara Augusta, CITCEM, Braga.

ESPARZA, A., 1987, Los castros de la Edad del Hierro del noroeste de Zamora, Diputación de Zamora, Zamora.

FERNÁNDEZ, A. 2008, Cerámicas del mundo castrexo del NO Peninsular. Problemática y principales producciones, en D. BERNAL y A. RIBERA (eds.), Cerámicas hispanorromanas. Un estado de la cuestión, Cádiz, 221-245.

HALES, S. y HODOS, T., 2010, Material culture and social identities in the ancient world, Cambridge University Press, Cambridge, Nueva York.

HEVIA, S. y MONTES, R., 2009, Cerámica Romana Altoimperial de fabricación regional del Chao Samartín (Grandas de Salime, Asturias), Cuadernos de Prehistoria y Arqueología de la Universidad Autónoma de Madrid 35, 27-190.

HEVIA, S., MONTES, R. y BENÉITEZ, C., 1999, Cerámica común romana del Chao Samartín (Grandas de Salime - Asturias): Vajilla de cocina y almacenamiento, BSAA 65, 11-48.

HIDALGO, J. M. y RODRÍGUEZ, E., 1987, Castro de Fozara. Campaña 1984, Arqueoloxía/Memorias 9, Xunta de Galicia, Santiago de Compostela.

HUGUET, E., 2013, El material más usado por los antiguos: la cerámica común y de cocina, en A. RIBERA I LACOMBA (coord.), Manual de cerámica romana. Del mundo Helenístico al Imperio 
Romano, Museo Arqueológico Regional, Madrid, 291-330.

LAPUENTE, M. P., PÉREZ-ARANTEGUI, J., AGUAROD, C. y ALCORTA, E., 1996, Caracterización de imitaciones provinciales micáceas de engobe interno rojo-pompeyano en el norte de la península ibérica, Actes du colloque de Périgueux 1995, Supplément à la Revue d'Archéométrie, 89-94.

LÓPEZ, C., 2007, Aportaciones al estudio del comercio romano a través de la cerámica de importación: la Terra Sigillata de la provincia de A Coruña, Brigantium, A Coruña.

LOZANO, H., BARBAZÁN, S. y RAMIL, E., 2016, Cerámica común romana no torneada de difusión aquitano-tarraconense en castros de la costa de Lugo, Boletín Ex Officina Hispana 7, 47-51.

LOZANO, H., CAAMAÑO, J. M., RAMIL, E. y BARBAZÁN, S., 2015, El yacimiento galaicoromano de Punta do Castro (Barreiros, Lugo). Nuevas aportaciones, Férvedes 8, Museo de Prehistoria e Arqueoloxía de Vilalba, Vilalba, 221-229.

MARTINS, M., 1987, A cerâmica proto-histórica do Vale do Cávado: tentativa de sistematização, Cadernos de Arqueologia II/4, 35-77.

MAYA, J. L., 1988, La cultura material de los castros asturianos, Estudios de la Antigüedad 4/5, Universitat Autònoma de Barcelona, Barcelona.

MAYA, J. L. y CUESTA, F., 2001, El castro de la Campa Torres. Período prerromano, VTP Editorial / Ayuntamiento de Gijón, Gijón.

MORAIS, R. y SOUSA, M. J., 2015, Bracara Augusta Figlina. Capita selecta, en A. MARTínEZ, M. ESTEBAN y E. ALCORTA (eds.), Cerámicas de época romana en el norte de Hispania y en Aquitania. Producción, comercio y consumo entre el Duero y el Garona, EX OFFICINA HISPANA. Cuadernos de la SECAH 2, Bilbao, 15-31.
MORILLO, A., AMARÉ, M. T. y GARCÍA, V., 2005, Asturica Augusta como centro de producción y consumo cerámico, en C. FERNÁNDEZ y P. GARCÍA (eds.), Unidad y diversidad en el arco atlántico en época romana. III Coloquio Internacional de Arqueología en Gijón, BAR International Series 1371, Oxford, 139-161.

RAMIL, E., 1997, El castro de Vixil (Vilalba, Lugo). Estudio de materiales y nuevas perspectivas, Férvedes 4, Museo de Prehistoria e Arqueoloxía de Vilalba, Vilalba, 81-105.

RAMIL, E., 2010, Análisis del objeto arqueológico: morfología descriptiva y tipología, en A. J. LÓPEZ y E. RAMIL (eds.), Arqueoloxía: Ciencia e Restauración, Monografías 4, Museo de Prehistoria e Arqueoloxía de Vilalba, Vilalba, 155-166.

RAMIL, E., FERNÁNDEZ, C., RODRÍGUEZ, C., LÓPEZ, C. y FERNÁNDEZ, P., 1995, El yacimiento de Punta do Castro (Reinante, Barreiros, Lugo). Materiales de superficie y perspectivas, Férvedes 2, Museo de Prehistoria e Arqueoloxía de Vilalba, Vilalba, 87-115.

REY, J., 1991, Yacimientos castreños de la vertiente atlántica. Análisis de la cerámica indígena, Universidade de Santiago de Compostela, Santiago de Compostela.

SÁNCHEZ, F. J. y FERNÁNDEZ, M. D., 1985, La corona y el castro de Corporales I. Truchas (León). Campañas de 1978 a 1981, Excavaciones Arqueológicas en España 141, Madrid.

SILVA, M. A. D. da, 1997, A cerâmica castreja da Citânia de Briteiros, Sociedade Martins Sarmento, Guimarães.

VIGO, A., 2007, O castro de Zoñán (Mondoñedo, Lugo). Escavacións 2002-2004, Concello de Mondoñedo, Mondoñedo.

VILLA, A., MONTES, R., HEVIA, S., MENÉNDEZ, A., SÁNCHEZ, E. y MADARIAGA, B., 2008, El ajuar doméstico en los castros de Asturias (cerámica, vidrio, metalurgia y orfebrería), en La prehistoria en Asturias, 753-800. 